\title{
DESCRIÇÃO DO IMAGO MACHO DE CAENIS CUNIANA FROEHLICH, COM NOTAS BIOLOGICAS (EPHEMEROPTERA, CAENIDAE)
}

\author{
Elidiomar Ribeiro da Silva ${ }^{1}$
}

\begin{abstract}
DESCRIPTION OF THE MALE IMAGO OF CAENIS CUNIANA FROEHLICH WITH BIOLOGICAL NOTES (EPHEMEROPTERA, CAENIDAE). The male imago of Caenis cuniana Froehlich, 1969 is for the first time described, based on one specimen from Maricá, Rio de Janeiro, Brazil. Notes on taxonomy and biology of the species are added.

KEY WORDS. Ephemeroptera, Caenidae, Caenis cuniana
\end{abstract}

FROEHLICH (1969) descreveu Caenis cuniana (Ephemeroptera, Caenidae) a partir de ninfas e adultos (fêmeas) procedentes do Estado de São Paulo; diversas gerações de fêmeas partenogenéticas foram obtidas por aquele autor, em laboratório. A espécie foi enquadrada em Caenis Stephens, $1835 \mathrm{com}$ base em caracteres da ninfa, a despeito desta apresentar garras denteadas, característica até então não encontrada no gênero (THEW, 1960; FROEHLICH, 1969). Posteriormente, MALZACHER (1986) registrou a espécie para o Pará (como "Caenis ? cuniana").

Durante estudos sobre a entomofauna aquática de uma área de restinga em Barra de Maricá, município de Maricá, Rio de Janeiro, foram colecionados ninfas e adultos de C. cuniana. Do total de 17 adultos coletados em campo ou criados em laboratório, obteve-se um único exemplar macho, aqui descrito. A eclosão de ovos não fecundados demonstrou que a espécie é também partenogenética em Barra de Maricá.

\section{Caenis cuniana Froehlich, 1969}

Figs 1-5

Imago macho. Coloração geral castanha. Cabeça castanha, com as suturas escurecidas. Base dos ocelos e escapo antenal castanho-escuros. Pronoto castanho, com as suturas escurecidas. Asas claras, com as nervuras maiores castanhas; três nervuras transversais presentes na metade apical do setor subcostal; escassez generalizada de nervuras transversais em outros setores; quatro nervuras intercalares à $\mathbf{R}_{2}$. Prosterno estreitado anteriormente. Mesonoto castanho-amarelado. Metanoto castanho. Pernas castanho-claras; fêmures com uma mancha mediana longitudinal e outra apical, ambas castanho-escuras;

1) Departamento de Zoologia, Universidade Federal do Rio de Janeiro, Caixa Postal 68044, 21949-900 Rio de Janeiro, Rio de Janeiro, Brasil. Pós-graduação em Zoologia, Museu Nacional do Rio de Janeiro. 

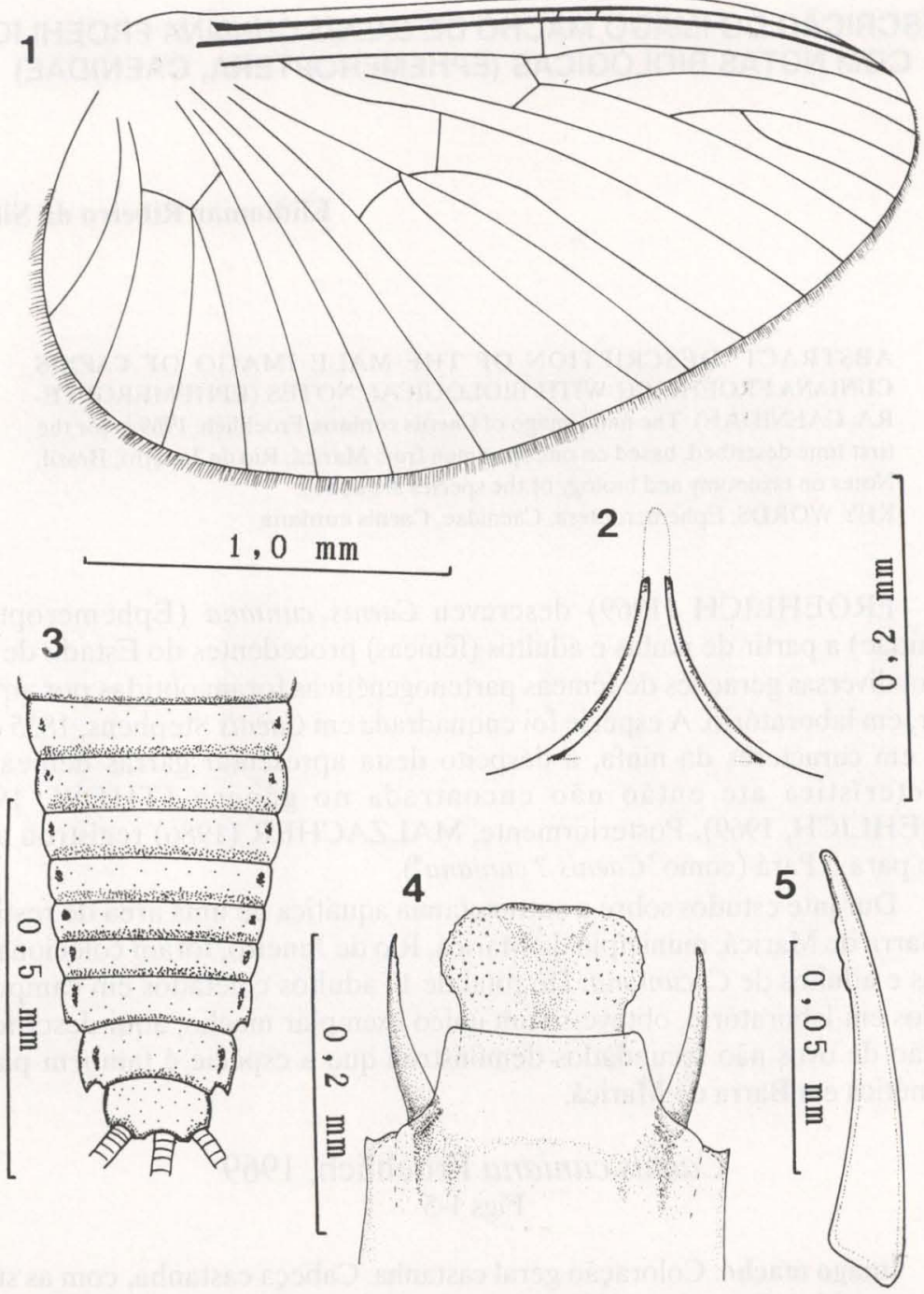

Figs 1-5. Caenis cuniana, imago macho. (1) Asa esquerda; (2) contorno do prosterno; (3) tergitos abdominais; (4) genitália, vista ventral; (5) fórceps genital esquerdo.

metade distal das tíbias castanho-escuras. Tergitos abdominais pardo-amarelados, com manchas estigmáticas castanho-escuras. Margens posteriores do $8^{\circ}$ e do $9^{\circ}$ segmentos com pequenos espinhos laterais. Filamentos caudais esbranquiçados. Fórceps genital longo, esclerosado e progressivamente afilado até o ápice agudo; margem interna com três dentículos subapicais. Pênis único, em forma de clava, com lobos totalmente fusionados, sem qualquer vestígio externo remanescente dessa fusão. Medidas (em mm): corpo 1,9; asa 2,0; perna anterior 1,8 (fêmur 0,5 ; tíbia 0,6 ; tarso 0,7); perna mediana 1,0 (fêmur 0,4, tíbia 
0,4 ; tarso 0,2 ); perna posterior 1,5 (fêmur 0,6 ; tíbia 0,6 ; tarso 0,3 ); cerco 6,4 ; filamento mediano 8,4.

Material estudado. Brasil, Rio de Janeiro, Maricá, Restinga de Barra de Maricá: um imago macho e um imago fêmea, 01-VI-1989, E.R. da Silva leg. (em luz); um subimago fêmea, 02-VI-1989, L.F.M. Dorvillé \& J.L. Nessimian leg.; um imago fêmea, 07-X-1989, R.M.A. Lemos \& P.D. Sampaio leg; oito subimagos fêmeas, 07-08-X-1989, R.M.A. Lemos \& P.D. Sampaio leg. (coletadas como ninfas e criadas em laboratório); três subimagos fêmeas, 07-IX-1991, E.R. da Silva leg. (coletadas como ninfas e criadas em laboratório); dois subimagos fêmeas, 27-IX-1991, L.F.M. Dorvillé (coletadas como ninfas e criadas em laboratório); 125 ninfas de primeiro estádio, obtidas a partir de um subimago macho (emergência: 13-IX-1991), 215 ninfas de primeiro estádio, obtidas a partir de dois subimagos fêmeas (emergências: 14-IX-1991), 07-IX-1991, E.R. da Silva leg. Os exemplares estudados encontram-se depositados na Coleção Entomológica do Departamento de Zoologia, Instituto de Biologia, Universidade Federal do Rio de Janeiro.

\section{BIOLOGIA}

Ninfas de C. cuniana foram coletadas no Brejo-canal de Itaipuaçu, situado entre os dois cordões arenosos da Restinga de Barra de Maricá ( $22^{\circ} 56^{\prime}$ S; $42^{\circ} 50^{\prime} \mathrm{W}$ ). $\mathrm{O}$ brejo apresenta águas rasas e ácidas ( $\mathrm{pH}$ em torno de 5,0), com teor de oxigênio dissolvido variando de $11 \%$ a $12 \%$. As macrófitas aquáticas dominantes são Eleocharis sellowiana Kunth. (Cyperaceae), Sagittaria lancifolia L. (Alismataceae) e Nymphoides humboldtianum (H.B.K.) O. Kuntze (Menyanthaceae). As ninfas situam-se no fundo ou por sobre a vegetação, apresentando hábito raspador. $\mathrm{O}$ conteúdo digestivo revelou a presença de desmidiáceas, cianofíceas, clorofíceas, fibras vegetais e detritos orgânicos. A freqüência populacional de $C$. cuniana atinge valores máximos entre a primavera e o verão (de outubro a janeiro). Além do Caenidae, há outro efemeróptero ocorrente na região, o Baetidae Callibaetis guttatus Navás, 1915 (DA SILVA, no prelo).

Parte do ciclo biológico de C. cuniana foi acompanhada em laboratório. A emergência das subimagos ocorreu entre às 18:00 e 20:00 horas. Como foi verificada a eclosão de ovos não fecundados, ficou caracterizada a ocorrência de partenogênese, estratégia reprodutiva já registrada para a espécie (FROEHLICH, 1969).

Em laboratório, as subimagos morreram logo após a emergência, não chegando sequer a atingir o estágio imaginal. Segundo observado, as fêmeas não realizam uma oviposição tradicional, morrendo com a maioria dos ovos no seu interior, ao contrário dos exemplares estudados por Froehlich em São Paulo, que realizavam a postura logo após a ecdise imaginal. Nos exemplares de Maricá, os ovos vão sendo liberados à medida que o corpo da fêmea entre em decomposição. Algumas eclosões foram observadas ainda na cavidade abdominal da fêmea morta.

Posturas provenientes de três fêmeas, obtidas a partir de ninfas criadas 
em laboratório, foram acompanhadas até as eclosões. Para o cálculo do tempo de maturação dos ovos, considerou-se a data de oviposição como sendo a mesma da emergência da fêmea. Os resultados estão sumarizados na tabela I.

O número de ovos por postura variou entre 100 e 199. À temperatura ambiente de $22,0^{\circ} \mathrm{C}$, em média, o tempo decorrido entre postura e eclosão foi de nove a 25 dias, e a taxa de fecundidade variou entre $62,8 \%$ e 78,0\%. Esses valores são próximos aos registrados por FROEHLICH (1969).

Tabela I. Tempo decorrido entre a postura dos ovos e a eclosão das ninfas de C. cuniana, em laboratório.

\begin{tabular}{|c|c|c|c|c|c|c|c|c|c|c|c|c|c|c|c|c|c|c|c|c|}
\hline \multirow{2}{*}{$\begin{array}{l}\text { Data da emergência } \\
\text { do subimago fêmea }\end{array}$} & \multirow{2}{*}{$\begin{array}{l}\text { Número } \\
\text { de ovos }\end{array}$} & \multicolumn{17}{|c|}{ Dias após à postura } & \multirow{2}{*}{$\begin{array}{l}\text { Total de } \\
\text { eclosôes }\end{array}$} & \multirow{2}{*}{$\begin{array}{c}\text { Taxa de } \\
\text { fecundidade } \\
(\%)\end{array}$} \\
\hline & & 9 & 10 & 11 & 12 & 13 & 14 & 15 & 16 & 17 & 18 & 19 & 20 & 21 & 22 & 23 & 24 & 25 & & \\
\hline $13-I X-1991$ & 199 & 0 & 7 & 56 & 21 & 13 & 7 & 7 & 4 & 4 & 3 & 2 & 0 & 0 & 0 & 0 & 0 & 0 & 125 & 62,8 \\
\hline $14-I X-1991$ & 100 & 25 & 31 & 15 & 2 & 2 & 0 & 2 & 0 & 1 & 0 & 0 & 0 & 0 & 0 & 0 & 0 & 0 & 78 & 78,0 \\
\hline $14-I X-1991$ & 182 & 0 & 36 & 18 & 40 & 16 & 11 & 6 & 3 & 1 & 1 & 1 & 1 & 3 & 0 & 0 & 0 & 1 & 137 & 75,3 \\
\hline
\end{tabular}

\section{DISCUSSÃO}

Adultos de C. cuniana podem ser diagnosticados pela combinação dos seguintes caracteres: (1) presença de três nervuras transversais subcostais na metade apical da asa (Fig. 1); (2) escassez generalizada de nervuras transversais (Fig. 1); (3) prosterno estreitado anteriormente (Fig. 2): (4) fórceps genital esclerosado, longo e afilado, com três dentículos subapicais (Figs 4-5); (5) lobos do pênis fusionados, em forma de clava (Fig. 4).

As peças genitais do macho de C. cuniana seguem o padrão típico do gênero Caenis, caracterizado por apresentar fórceps reto e obtuso ou agudo (THEW, 1960). Ainda quanto à genitália, C. cuniana enquadra-se no grupo "mais especializado" do gênero, que, segundo THEW (1960), apresenta os lobos do pênis inteiramente fusionados. C. cuniana parece mais proximamente relacionada a C. fittkaui Malzacher, 1986 e C. candelata Malzacher, 1986, descritas para a Amazônia Brasileira, que também apresentam fórceps longo, bem esclerosado e pênis em forma de clava (MALZACHER, 1986).

\section{REFERÊNCIAS BIBLIOGRÁFICAS}

DA SILVA, E.R. (no prelo). Descrição da ninfa de Callibaetis guttatus Navás, 1915, com notas biológicas e comentários sobre a imago (Ephemeroptera: Baetidae). An. Soc. ent. Brasil 20 (2).

FROEHLICH, C.G. 1969. Caenis cuniana sp.n., a parthenogenetic mayfly. Beitr. Neotrop. Fauna 6 (2): 103-108.

MALZACHER, P. 1986. Caenidae aus dem Amazonasgebiet (Insecta, Ephemeroptera). Spixiana 9 (1): 83-103.

THEW, T.B. 1960. Revision of the genera of the family Caenidae (Ephemeroptera). Trans. Amer, ent. Soc. 86: 187-205.

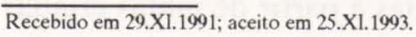

